\title{
Conceptions on the Protagonism of Women Fishing
}

\section{Rosiane Rocha Oliveira Santos, Josenilton Nunes Vieira, Deise Cristiane do Nascimento, Cláudia Maria Lourenço da Silva, Vânia Cristina Lasalvia, Antônio de Santana Padilha Neto}

Faculdade de Ciências Aplicadas e Sociais de Petrolina, Juazeiro/Bahia, Brazil

Email: rosi.rocha@facape.br, josenilton.vieira@facape.br, deise.nascimento@facape.br, claudia.lourenco@facape.br, vania.lasalvia@facape.br, padilha.neto@facape.br

How to cite this paper: Santos, R. R. O., Vieira, J. N., do Nascimento, D. C., da Silva, C. M. L., Lasalvia, V. C., \& de Santana Padilha Neto, A. (2019). Conceptions on the Protagonism of Women Fishing. Advances in Applied Sociology, 9, 258-268. https://doi.org/10.4236/aasoci.2019.97020

Received: May 7, 2019

Accepted: July 5, 2019

Published: July 8, 2019

Copyright () 2019 by author(s) and Scientific Research Publishing Inc. This work is licensed under the Creative Commons Attribution International License (CC BY 4.0).

http://creativecommons.org/licenses/by/4.0/

\begin{abstract}
Despite the positive rates of inclusion of women in the labor market in recent decades, there is still much to be done by the social and cultural equality of labor between the sexes. Regarding that the various professional activities still prevail sexual divisions of labor and performance of Angari of Artisanal Fisheries in Juazeiro/BA, these relationships are not very different. This work is the result of a survey conducted with women living in Angari community in Juazeiro/BA in order to assess the activities carried out by women in fishing activities as well as meet the traditional knowledge of that fishing-related community and which ones are passed on to younger people by these women. Throughout the paper, we describe what are the activities carried out by women and their culturally constructed social invisibility, women of the difficulties to maintain the support of their families and the challenges for the transmission of traditional knowledge to the younger people. The work also brings real proposals in order to disseminate the emerging need for public infrastructure policy, health and legalization of the activities developed by the fisherwomen of Angari.
\end{abstract}

\section{Keywords}

Artisanal Fisheries, Female Role, Traditional Knowledge

\section{Introduction}

Known as the river of national integration, the San Francisco garter regions such as Southeast and Midwest to the Northeast born in Serra da Canastra in Minas Gerais, the São Francisco is divided into four sections: the Upper São Francisco, 
which runs from its headwaters to Pirapora in Minas Gerais; the East, Pirapora, where begins the navigable stretch to Remanso in Bahia; the Lower Basin of Remanso to Paulo Afonso in Bahia; and the Low, Paulo Afonso to the mouth.

The Rio San Francisco or Opara-originally called by the natives of San Francisco Tupi that means dizzy, lost, who knows where it goes aimlessly-bathes the states of Minas Gerais, Bahia, Pernambuco, Sergipe and Alagoas. It is in the vicinity of the river, seen in much of the Brazilian semiarid region, which forms the Angari community in Juazeiro/BA, where women residing in this place are the protagonists in carrying out related activities directly and/or indirectly to the activities of traditional fishing; these same women also experience how difficult socioeconomic conditions and especially gender relations, which is also set in the context of community.

About this female role is noteworthy that women were the protagonists in the community training which has more than 120 years, since the historical formation of the neighborhood is intrinsically associated with women who worked as washerwomen clothes by the River San Francisco, in which to help support their families, they washed clothes and they settled on the river (FLAG SON \& PEREIRA, 2011).

With the growth of the community and the increase in production demands to meet the city's needs, women also entered the accomplishment of tasks related to traditional fishing as "helpers" in fishing or cleaning and processing of fish, but also continued the responsibility of transmission of traditional knowledge related to community experiences in the context of the Rio São Francisco.

In general, we can understand the Artisanal Fisheries second Diegues (1973) as one in which fishers work and fishermen in catching and landing their catch, alone, may use family labor or other hand-employment work. In this sense, we conducted this study in April and May 2014 with a qualitative approach, seeing identified practices developed by women and the importance of women's contribution to the Artisanal Fisheries supporting their families, even describing the transmission of related traditional knowledge fishing among women of the community.

\section{Methods and Techniques}

For this work is done semi-structured interviews with 20 residents $^{1}$ the community, in their homes, aged between 30 and 70 years with active exercise or who have already performed activities related to fishing. In addition to the semi-structured interviews we have adopted a policy of data collection tools and other daily records, informal conversations and observations of activities. In the semi-structured interview, the researcher organizes a set of questions (script) about the subject being studied, but allows, and sometimes even encourages, the interviewer to speak freely about issues that arise as a consequence of the main theme.

${ }^{1}$ Identities will be revealed only by the initials of the names of the interviewees. 
They have also held fishing visits to Cologne for the acquisition of information about the history of the community. Throughout the work are presented theoretical basis for discussions of the inferred reflections on research as Neiva (1990), Diegues (2004), Montenegro et al. (2001), Sarti (2005) and Saffiotti (1987) among others.

Were investigated through interviews, embodiments of the direct and indirect activities of fishing for the maintenance of family income, the main challenges to the sustainability of families through fishing activities, which are the main traditional knowledge related to the activities and their transmission such knowledge to the younger women of the community.

\section{Results and Discussion}

With the intensification of residents and residents on the edge of the Rio São Francisco, the Angari the community has grown and this growth led to the need for formalization and recognition of the territory as a neighborhood. The Regional Superintendent of Juazeiro recognized the neighborhood by the end of the nineteenth century, but the whole occupation of Angari occurred irregularly chronic form, as the waiting for their husbands, that went out to fish passing days on the island, women tended to facilitate the livelihood of their families occupying the riverside space with dwellings that should be temporary.

As stated, the production activities, network repair and treatment of fish required increasing female participation, the traditional fishing then becomes a reality also women. Although it is new to the women of the community Angari, the Artisanal Fishing is considered one of the oldest activities carried out by mankind and is presented in historical data brought by Diegues (2004: p. 17), as a previous activity to the Neolithic (12 billion and $4000 \mathrm{BC}$ ) "[...] fishing is one of the oldest activities carried out by humans prior to the Neolithic period. The remains of pottery, oyster shells and mussels found in Scandinavia, inpre-Neolithic period, attest to the importance of molluscs in human nutrition".

Over the centuries, billions of people worldwide and more than four million people in Brazil depend directly or indirectly on fishing. Neiva (1990) corroborates stating that the fishing activity before 1960 in Brazil was predominantly handmade, with production geared to the domestic market. However, according to Cabral (1997) even sothis type of fishing method received not before and neither has received over the years significant government incentives, although the main activity for a significant portion of the coastal and inland population of Brazil as well as being a very important activity in that supplies the local and regional market.

This research showed that the lack of incentives and investments related to Artisanal Fisheries, in the case of residents of the community Angari, was reported as one of the many difficulties because it reflects the indifference of the 
government towards traditional fishing communities in general. In the interviews, one of the biggest challenges cited by fishers was the fish shortage, which is precisely the ineffectiveness of the São Francisco River revitalization policies resulting in discouragement for fishers and providing a search for other activities outside of reality Artisanal Fisheries and go to work in other people's houses as maids, caretakers of children and the elderly; in their own homes as manicures, crosswalks clothing, or several spaces as sellers in the trade, sellers of gambling, etc.

Other studies show the fight in fisherwomen's daily life and traditional fishermen to ensure their survival, saying that this struggle includes not only aspects related to the act of fishing, but also the ways to secure employment and income, as a result of fishing uncertainties many fishermen are seeking alternatives to ensure the livelihood of their families. For Montenegro et al. (2001), fishermen are part of an ecosystem network and their interactions should not be seen only from the point of view of the use and ownership of resources, but in the context of social relations.

We note from this principle socio-cultural relationship of gender in the activities of traditional fishing with the intention to assess the main challenges for women having as observation point the factor of "being a woman" or "woman without a husband" in Artisanal Fisheries and trouble carrying out activities from this considering that "fulfilling the male role of provider does not qualify, in fact, a problem for the woman, used to working, especially when precision; for her the problem is to keep the size of the respect given by the male presence" (SARTI, 2005: p. 67).

In fact women revealed that the difficulty is not necessarily keeping the house, but the difficult path taken every month to be able to meet the family's needs:

Difficult is not pulling no network, so we do playing. The hard part is going to sleep in the middle of the river as a woman alone. My kids did not want to go, nor do I want them to go. I want is that they study... (a pause to look at the river and then resumes) is difficult to risk going alone to the middle of the river without knowing it will come back, having to leave small children with someone and if not I have with whom to leave, take them as I have done a lot. But it's dangerous, $P$ ve seen too many things in this life ... (JSF64 years)

This danger presented by the interviewee is directly related to thefts, robberies, deaths, because as they showed in the interviews, in times of good fishing is necessary "to go to an island in the middle of nowhere and stay there waiting for God to send those big fish for us to eat and then treat others to bring to town to sell and ensure the month. Because here in berada it is only the smaller fish even" (VMS 53 years). In such cases, some have said they will no longer the fisheries in the middle of the island, are only on the river in the community.

We identified although the male figure in the fishing is dominant even in the negotiation process and sale of fish. Some fishers say they serve only as bait to 
middlemen ${ }^{2}$ because they can not sell the fish in a short period of time and not have a structure to keep the fish longer in residence.

With all the processes that underlie the diverse realities of women community of fishers, we identified that much has already abandoned the activities of fishing. Of the 20 interviewed only 03 are in active fishing activities; 08 no longer exert any kind of linked to fishing activity due to hazards, shortage of fish, income uncertainty, physical wear, etc.; 09 and perform activities such as making and repair networks, patch and decorative boats, cleaning and sale of fish (purchased with other fishermen) at home, free or fair municipal market.

Still, the group working in support of fishing activities, claims that income, even with the receipt of social benefits such as Bolsa Familia, Insurance closed season $^{3}$, Among others, it is not enough to keep a family. In contrast, those still actively maintains fishers claim that, despite the low income you can still:

"Keep the house and the children, because with this river that God has given us is not unemployed, there's always something to do and to eat, even if only to eat fish, even if abuse fish but have fish! Imagine you work around these store that leave have nothing to eat right? So we always have, that God gives. At least the fish with flour does not go hungry or have to go ask. Worse who has no river. Worse who has neither fish right?" (ESB 40 years)

This speech reaffirms the design of Cavalcante (1989) which points out that in addition to the important role in food production, artisanal fishing is a strong social indicator, which contributes to the establishment of families in their regions of origin, avoiding migration for urban centers and the consequent "degrading" conditions found in large cities. Also supports other conception affirmed Malvezzi (2007) comprising the religious dimension as an intrinsic part of the people and directly linked to the characteristics of struggle and resistance was shaping up as part of knowledge transfer processes in the community.

\subsection{Between Tradition and Contemporary: The Plight of Women in the Transmission of Traditional Knowledge to Younger People}

Among the knowledge traditionally transmitted to Angari women most are directly linked to the Rio São Francisco and, more than that, the knowledge part of the daily lives of fishers or that perform tasks related to fishing. Bornheim (1987: p. 18) explains that tradition comes from the Latin traditio and means "also deliver means the act of passing something to another person, or to move from one generation to another generation." According to the dictionaries we find the word related to verb tradire as oral knowledge, that is, by tradition, ${ }^{2}$ People who usually do not fish, but buy directly into the hands of fishermen and fisherwomen to bring to the fair or other points of trade to have regularity and infrastructure to ensure the durability of the fish.

${ }^{3}$ The social benefits Bolsa Familia and Insurance closed season are guaranteed by the Federal Government. Bolsa Familia guarantees the completion of family income throughout the year for families with incomes up to three minimum wages. But the closed season Insurance is ensured for fisherwomen and fishermen registered in the period of four months of fish reproduction. 
something is said and said is passed, released from generation to generation.

It is important to highlight that we rely on in the design of Brandão (1996) for the definition of community considering that "a group of people who live in a certain physical and geographical space, with a complex of cultural diversity: economic, political and social that interact in a dynamic process of relationships" (Brandão, 1996: p. 39).

According to the women, even the simplest activities, like going swimming in the river, they are permeated by knowledge acquired with the mother, father, sisters or other older family members and/or community. In interviews women elencaram diverse knowledge traditionally learned related to fishery times like praying and/or cringe-entering the river or on the boat, prayers to bring the fish, take with you a little smoke to offer the Nego D'water ${ }^{4}$ (More legend reported by fishers in interviews); related to religiosity as active participation infeast of St. Peter, light candles to light the way of souls lost in the river, prayers for the fisherman or fisherwoman did not get lost or find their way into the river, prayers not to miss the boat; health-related knowledge as the use of medicinal plants of the river, prayers for healing and even related to menstrual periods of women, which claimed that if the woman is fishing in this period can ward off fish.

Despite this rich diversity of knowledge that makes the community, the residents point out great difficulty in transmitting it to younger people stating that there is a lack of interest from them in learning. As the age of our initial research goal was above 29 years do not seek questioning youth and adolescents directly, but asked to older what forms of transmission of knowledge and what are the biggest obstacles encountered by them for such transmission.

We identified through the testimonials, that the only way of transmitting knowledge traditionally learned in this community is the oral transmission, where mothers will tell the stories and stories for his daughters and sons from childhood:

Many of the stories I learned there (points to the tree of Juazeiro ${ }^{5}$ near the residence) under that standing Juazeiro. My mother washed the clothes and I and my brother was playing. While quarava clothing she told the story that everyone was with the eye-popping eye. And if any noise get in the way we took fright. It was good, very good, but today no one wants to lose more time under foot stick no more. The boy wants is videogame, computer. Today no one gives more heed to older ... not only is behind us when the people of the college, to search, but who lives here does not even there. (LSB 70 years)

As shown in speaking up, despite the interest in conveying knowledge and seized historically constructed, women can barely keep the stories alive in the

${ }^{4}$ According to the fishermen and fisherwomen account is a black man who lives in the river to save it. If the fishermen do not take smoke for him to go fishing, the Nego D'water turns the boat fisherman and does all the fish disappear in the river.

${ }^{5}$ Jujube (commonly called Jua foot or simply Juá) is the tree name that gave rise to Juazeiro city where the survey was conducted. 
minds of their girls and boys are young, teenagers or even children. This sets a detachment framework of younger people from the broad dissemination of technology that every day are more accessible allowing access to social networks via mobile phones, personal computers in Internet cafes etc. According to the women interviewed, the younger crowd says it has no interest to perpetuate the activities related to Artisanal Fisheries for not bringing stable and profitable financial income to sustain a family.

Additionally, another critical factor that deserves attention was cited by 04 residents emphatically was the involvement with legal and illegal drugs has become a constant in the lives of adolescents and young men a few years ago and more recently of teenagers female which requires great attention of the authorities to this situation of social vulnerability that can, in addition to being a harmful process for the physical and family health, become one of the worst forms of prevention of transmission and/or recovery of traditional knowledge .

So while the respondents report that do not want their children to remain in fishing activities precisely because the aspects of low and uncertain income, they claim to want to convey traditional knowledge to perpetuate the history of the community and knowledge of the river, its legends and rites above claiming that the strengthening of traditional roots in the imagination of younger people is also a cultural tool of knowledge and respect for your own body.

Was consensual women admit the lack of interest from younger people, but the same state that still persist in conveying this knowledge between generations, as the transmission of knowledge orality help, for its ease of transmission/access, but at the same time it becomes more suitable to let the knowledge "fall by the wayside."

Goody and Watt (2006) argue that the oral transmission of knowledge connect the transformation of content transmitted to the economic aspects, so that this transformation of content occurs through the forgetfulness of some aspects and other increase, with the contribution of individual experiences for the formation of the oral tradition of a society and language as the main tool used in this process.

The authors call this process of memory and forgetting as "homeostatic organization of cultural tradition in illiterate societies" (GOODY \& WATT, 2006: p. 17). To Menget and Molinié (1992) these are the aspects that allow the recreation of certain parts of the content and characterize the historicity that tradition has.

Despite all the challenges listed women say where can this space for dialogue with the youngest members of the family mostly daughters and sons, add the values of knowledge traditionally learned, emphasizing its importance for the construction of historical knowledge and cultural of realities of their community. These women seek value their history and memory, constructing and transmitting a coexistence culture with the locality respect, especially the aspects of nature and religion. 


\subsection{Woman Things: The Sexual Division of Labor and Social Invisibility in Women's Tasks}

It is common practice in our society, which historically has endured for generations, that woman makes "women's things" and makes man "guy stuff". In its process of formation, growth and development, the child lives in a context that imposes rules according to their biological and training that will follow until you can make your own decisions and make your choices.

In different proportions, the girl/woman will experience different situations at the expense of boys/men in relation to work at home when dealing with family and especially in activities work that will develop. This differentiated education is clear, from the anthropological point of view, by Roque de Barros Homenurse when he states that " behavior of individuals depends on learning, a process we call endoculturação. A boy and a girl act differently not because of their hormones, but due a differentiated education" (Laraia, 2009: p. 20).

This process of differentiation will mediate the relationship to be established, the diverse interests and behaviors in society patriarchal where historicamente learned that working activities whose female protagonist must act are necessarily those related to domestic actions. Therefore, seeking to bring a reflection on the need to deconstruct the sexual division of labor ideas in the activities of traditional fishing, because this division affects strongly the invisibility of the activities carried out by women.

On women's role in Artisanal fisheries Maldonado (1986), Maneschy (1995) and Lima (2003) have discussed the existence of social and sexual division of labor noting that the male presence in the fisheries act is strongly majority. This division was also observed in the community and throughout the research identified that women's role in the sense of recognition, it is only for some families have only the woman as mantedora of family resources, for where there is the presence of the male figure women in their activities, they are seen only as helpers and, according Saffiotti (1987: p. 15) “whenever someone's activity is set as an aid, the responsibility is on the other", that is, still perpetuates the patriarchal model family maintainer man and woman only as an auxiliary".

Question the women about the existence of male participation (whether with children, husbands, brothers, etc.) in the division of household chores and the same stated that this is not a common reality among the families in the community, explaining that:

"They' ve both work right? So they' ve come home tired right? Fishing, the sun, the river ... And if the people who are a woman do, imagine if man will do something ... and also we do anyway have to clean the house, do the thing and let our way. Man does not know it not! So it's better not to ask. Then when it comes my husband and my grandson, who lives with me, Ill clean it, treat right?. Sometimes my daughter help; Sometimes no. But if I do not have untreated fish, or so goes to show you have no money" (AAS 58 years old).

Identified through this speaks several socially constructed as naturalization 
the obligation of housework for women for his alleged inclination to do so, the breadwinner maintenance responsibility for menial activities of man (which to be tired of these activities It is not touched with the responsibility to share the burden home with the women of the house), and last but most notably the focus of this research, the invisibility of the activities that are carried out by women before and after the arrival of the men at home.

The reality of these women is glaring because they possess double, triple working hours within their own homes without any assistance of others. Ie in the absence of man women do all the household activities and with their arrival, this same woman, even tired to deal with the pre-capture with nets patch and boat, and post-capture with processing and even the sale of fish.

Another couple participating in the research P. S. (42 years) and B.E.S. (38 years) treat the fish in the garage of the residence. The family has a better structure in relation to other residents for the treatment and storage of fish. BES is Pedagogy student from Universidade do Estado da Bahia (UNEB), has 02 children and has a grueling journey of study and work. She claims she has the help of partner and both share the tasks of activities related to fishing, but says:

For me to help him here in fisheries and time to treat or fix the tarrafas I have to wake up early is. First I give the house, take care of things and then come back here. When I finish I am tired, but then has the third part is to study. Ill make dinner, I leave everything ready and tidy me to go to college. It's exhausting, it's gone, but it's worth and also have to set an example for my children. But if the three of them at home helped eased me a lot because I was going to have time to study more (BES 38 years).

What actually is laid is the challenge of building this empowerment of women in their home through the recognition of activities that contribute to the family's livelihood. About this Saffiotti (1987: p. 15) states that "it is to share domestic life as well as leisure and guarantors activities of family support" thereby generating a value-identity of this female role in supporting their families by Artisanal fisheries.

\section{Final Considerations}

Recognizing some existing research with Angari fishermen of Juazeiro and his deeds, we seek to bring a difference to the productions conducting research focusing on the role of women in the field of traditional fishing and related activities. In this sense, the survey revealed the difficulty of women in ensuring the livelihood of their families by just acquired income in Artisanal Fisheries revealing that many need to undertake activities related to trade or in homes of others.

We realize, from this set of elements, there is an emerging need to understand the invisibility of women in the activities of Artisanal Fisheries and beyond comprehension, discuss with the task of organs ways to regulate the activities in the pre and post capture fish to generate a visibility to the work of women. 
Throughout the work, we observed that women have great difficulty in maintaining the livelihood of their families only with the income acquired in the activities of Artisanal Fisheries. We identify the various knowledge traditionally seized and built in the community and that they are transmitted, as in most traditional communities, orally. Furthermore, the interviewees list various obstacles that arise to ensure the transmission of traditional knowledge of their community for the younger people like setting up a great lack of interest of this audience.

It is necessary to note that, through the data it is clear that the community is in need of public policies for its infrastructure and especially educational policies that enhance the knowledge of the community in the school.

In this sense, in addition to evaluating the female role in supporting their families and transmission of traditional knowledge held by women of the community, from this work, we infer that it is urgent to promote actions that seek to evaluatively reframe the knowledge of the community, configurans do also as an instrument for the promotion of citizenship and the improvement of living conditions of artisanal fishers of Angari community.

As a practical meaning of the research, it is necessary to highlight the following points: the research provokes a reflection to think means to foment in the formal education strategies of valorization of the traditional knowledge; the research reveals the need for gender studies in the social sciences and human sciences aimed at the sexual division of labor that involves artisanal fishing, and therefore, it is necessary to do more research in this area to point out ways of valuing women's work. Finally, the research values the work developed by the Angari women and brings more visibility to the knowledge of these women, provoking other researches and the production of knowledge about them.

\section{Conflicts of Interest}

The authors declare no conflicts of interest regarding the publication of this paper.

\section{References}

Bornheim, G. (1987). The Concept of Tradition. In Tradition-Contradiction (152 p.). Rio de Janeiro: Zahar.

Brandão, C. R. (1996). The Difficult Mirror: Limits and Possibilities for an Experience of Culture and Education. Rio de Janeiro: IPHAN/Depron.

Cabral, C. A. R. (1997). Environmental education ma artisanal fishing for pink shrimp (Penaeus paulensis) in Rio Grande: Analysis of a Try (237 p.). Dissertation (Masters in Environmental Education), Rio Grande: FURG.

Cavalcante, R. R. (1989). The Brazilian Fishing-Its Resources, Policies and Strategies of National Interest (82 p.). México: Superior School of War/Department of Strategic Policy Studies.

Diegues, A. C. (2004). Fishing Building Societies: Readings in Maritime and Fishing Anthropology. São Paulo: Support Center for Research on Human Population and 
Wetlands Brazilian/USP.

Diegues, A. C. S. (1973). Fishing and Marginalization on the Coast. Master's Thesis, São Paulo: NUPAUB, CEMAR, University of São Paulo.

Goody, J., \& Watt, I. (2006). The Consequences of Literacy. São Paulo: Ed Paulistana.

Laraia, R. de B. (2009). Biological Determinism. In Culture: An Anthropological Concept (24th ed., 116 p.). Rio de Janeiro: Jorge Zahar.

Malvezzi, R. (2007). Semi-Arid: A Holistic View. Brasilia: Confea.

Menget, P., \& Molinie, A. (1992). Introduction. In P. Menget, \& A. Molinie (Eds.), La mémoire de la tradition (pp. 9-20). Paris: Société d'Ethnologie.

Montenegro, S. C. S., Nordi, N., \& Marques, J. G. (2001). Cultural Context, Ecological and Economic Production and Occupation of Fishing Areas by Pitu Fishing (Macrobrachium carcinus) in a Low Stretch San Francisco, Alagoas, Brazil. Interscience, $26,46$.

Neiva, G. S. (1990). Grants for the National Fisheries Policy. Fishing Terminal of Santos (TPS). Technical Publication.

Saffiotti, H. I. B. (1987). The Power of the Male. Sao Paulo: Modern.

Sarti, C. A. (2005). The Family as a Mirror: A Study on the Moral of the Poor (3rd ed.). São Paulo: Cortez. 